\title{
Oral Medicine Case Book: An intra-oral solitary Schwannoma of the lower lip, a rare diagnosis
}

\author{
SADJ September 2019, Vol. 74 No. 8 p448 - p450
}

G Abrahams' ${ }^{1}$, MT Peck², LXG Stephen ${ }^{3}$, J Opperman ${ }^{4}$

\section{CASE REPORT}

A 25-year-old clinically healthy female presented to the Oral Medicine Clinic at the University of the Western Cape, with a swelling on her lower lip. The swelling started following a knife injury to the affected area and was present for almost three years. No treatment was sought for the initial injury and the lesion has slowly increased over time. The lump was asymptomatic but the patient requested that it be removed for cosmetic reasons.

She had no significant medical history and her extra -oral examination revealed bilateral submandibular lymphadenopathy. Intra-orally, a $15 \times 15 \mathrm{~mm}$ exophytic soft tissue lesion was seen on the lower labial mucosa, across the midline. The lesion firm, broad based, non-tender on palpation and was the same colour as the surrounding mucosa (Figure 1).

In addition, a small scar was noted across the midline of the lesion possibly from her previously reported assault. She had poor oral hygiene with visible soft plaque and calculus deposits detected on all her molars as well as multiple carious lesions and missing teeth.

The palpable bilateral lymph nodes could be attributed to the multiple lower carious teeth. The differential

\section{Author affiliations:}

1. Gadidja Abrahams: $B C h D, M C h D$, Division of Oral medicine and Periodontics, Faculty of Dentistry, University of the Western Cape. ORCID Number: 0000-0002-3905-8977

2. Mogammad T Peck: BChD, MSc Dent, MChD, MRD RCSEd, FDS RCSEd. MDTFEd., Division of Oral medicine and Periodontics, Faculty of Dentistry, University of the Western Cape. ORCID Number: 0000-0002-4755-0574

3. Lawrence XG Stephen: BChD (UWC), PhD. (UCT), Division of Oral medicine and Periodontics, Faculty of Dentistry, University of the Western Cape.

ORCID Number: 0000-0002-1672-7672

4. Johan Opperman: BChD (US), MChD (UWC), Division of Oral Pathology, Faculty of Dentistry, University of the Western Cape; National Health Laboratory Service, Tygerberg. ORCID Number: 0000-0002-9684-6670

\section{Corresponding author: Gadidja Abrahams}

Division of Oral medicine and Periodontics, University of the Western

Cape. Dental Faculty, Fransie Van Zyl, Tygerberg Campus.

Tel: +27 (0)21937 3186

Email: gaabrahams@uwc.ac.za

Author contributions:

1. Gadidja Abrahams: Write up and clinical management - $70 \%$

2. Mogammad T Peck: Review $-10 \%$

3. Lawrence XG Stephen: Review - 10\%

4. Johan Opperman: Histology diagnosis - $10 \%$

\section{ACRONYMS}

$\begin{array}{ll}\text { MRI: } & \text { Magnetic Resonance Imaging } \\ \text { CT: } & \text { Computed Tomography }\end{array}$

diagnosis included a mucocele, salivary gland neoplasm, benign soft tissue neoplasm (based on rate of growth and clinical appearance), traumatic fibroma, or a swelling secondary to the initial trauma.

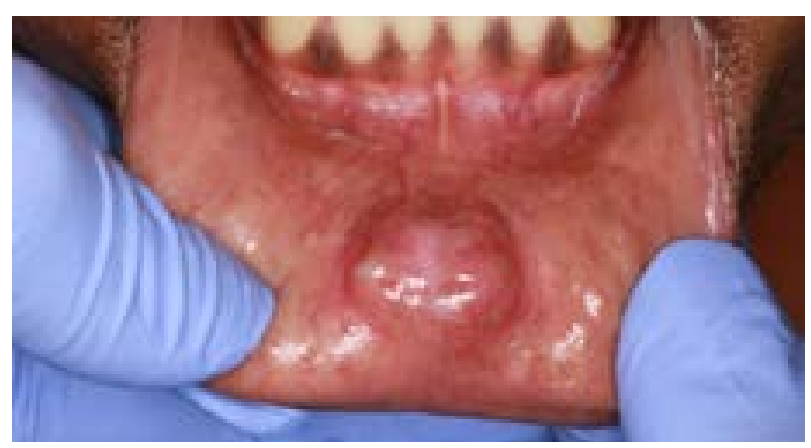

Figure 1. Initial clinical presentation.

\section{Management and diagnosis}

An excisional biopsy was performed under local anesthesia. A curvilinear incision was made superficially across the midline of the lesion. Thereafter, blunt dissection was performed to separate the lesion from the surrounding tissue. Following complete enucleation, primary closure was obtained using vicryl sutures.

Postoperative instructions were given and a follow up appointment scheduled one week later. The healing was uneventful at the follow up appointment and the patient was referred to the relevant departments for prophylaxis and management of the carious lesions.

The macroscopic examination revealed an oval, firm wellcircumscribed mass measuring $13 \times 8.5 \mathrm{~mm}$ (Figure 2). Microscopic examination showed a well circumscribed, encapsulated neoplasm comprising bland spindle-shaped cells with hyperchromatic nuclei, exhibiting a palisaded arrangement surrounding acellular eosinphilic areas (Verocay bodies) (Figure 3). A predominant "Antoni A" pattern was demonstrated throughout; with, focal "Antoni B" areas also present (Figure 4).

Immunohistochemical staining with S100 protein showed nuclear and cytoplasmic positivity in the spindle-shaped cells, confirming the Schwannian origin of the neoplastic cells (Figure 5). 


\section{DISCUSSION}

Schwannomas, also referred to as neurilemmoma or neurinoma, are rare encapsulated benign neural neoplasms of Schwann cell origin. ${ }^{1-7}$ Schwann cells form a thin barrier around each extracranial nerve fiber, and wrap larger fibers with an insulating membrane, forming the myelin sheath in order to enhance nerve conductance. ${ }^{8}$ First described by Verocay in 1910, these tumours were initially referred to as 'Neurinomas'. Thereafter, in 1935, the term 'Neurilemmoma' was proposed due to the nerve sheath elements associated with these tumours. ${ }^{4,7,9,10}$

Schwannomas occur along the course of somatic, cranial and autonomic nerves, and are more frequently associated with sensorial nerves. ${ }^{5,6,9}$ Schwannomas do not arise from cranial nerves I and II, because these nerves lack Schwann cells. ${ }^{11-13}$ Schwannomas arise in association with a nerve trunk and as it grows, displaces the nerve. Nerve impingement can become symptomatic. . $3,5,13$ Approximately $25 \%-45 \%$ of all extracranial Schwannomas occur in the head and neck region ${ }^{1-7,9-12,16-20}$ with only $1 \%$ seen intra-orally. $6,7,12,16-19$ Intra-oral Schwannomas are rare, with the tongue being the most common site affected, followed by the palate, floor of the mouth, buccal mucosa and lip. ${ }^{3-5,7,9,15,16}$ Furthermore, Schwannomas of the lip is the rarest reported clinical entity and is therefore generally not included in the differential diagnosis of a lower lip swelling. 1,3,6,10,12,14,17,20

Schwannoma of the lip was first described in 1969 and since then only a few number of Schwannoma cases of the lip have been reported. ${ }^{12,18}$ Moreover, as the Schwannoma of the lip enlarges, it also causes obvious aesthetic disfigurement for the patient and can lead to emotional distress. ${ }^{20}$ On occasion, it can arise centrally within bone, most commonly in the posterior mandible with concomitant bone expansion with associated pain and paresthesia.5,7 The tumour can affect individuals of all age groups but is most commonly found in the $2^{\text {nd }}$ and $3^{\text {rd }}$ decades of life, with no gender predilection. ${ }^{7,18}$

The aetiology remains unknown. Some causative factors such as rare genetic predisposition, spontaneous growth, external injury, and chronic inflammation have been postulated. ${ }^{20}$ Schwannomas are not usually associated with a history of trauma, even though post traumatic cases have been reported. ${ }^{7,13,17}$ Moreover, with the history of trauma in our case as well as the location, a Schwannoma was not considered as a differential diagnosis.

Clinically, Schwannomas are typically an asymptomatic solitary, freely mobile, submucosal mass characterized by slow growth and a smooth surface..$^{1,3,11}$ Clinical symptoms are variable depending upon the location, other symptoms may arise, such as dysphonia, nasal obstruction, dyspnea, dysphagia and oral pain. $.12,13,20$

Schwannomas are usually solitary lesions but infrequently may be multifocal. Multifocal lesions also occur in 1) multiple localised neurilemmomas; 2) in association with neurofibromas, in von Recklinghausen's

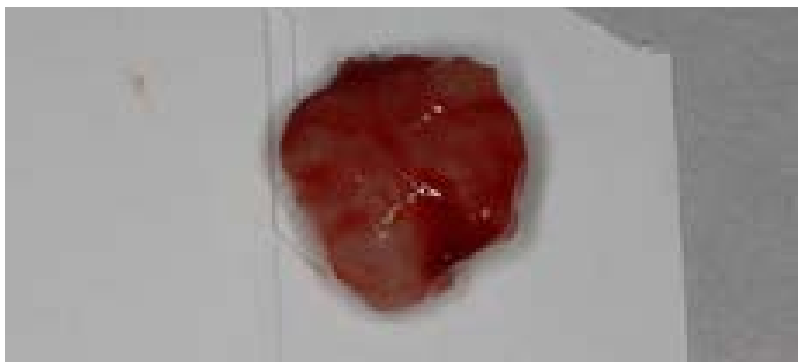

Figure 2. Macroscopic presentation of lesion following surgical excision.

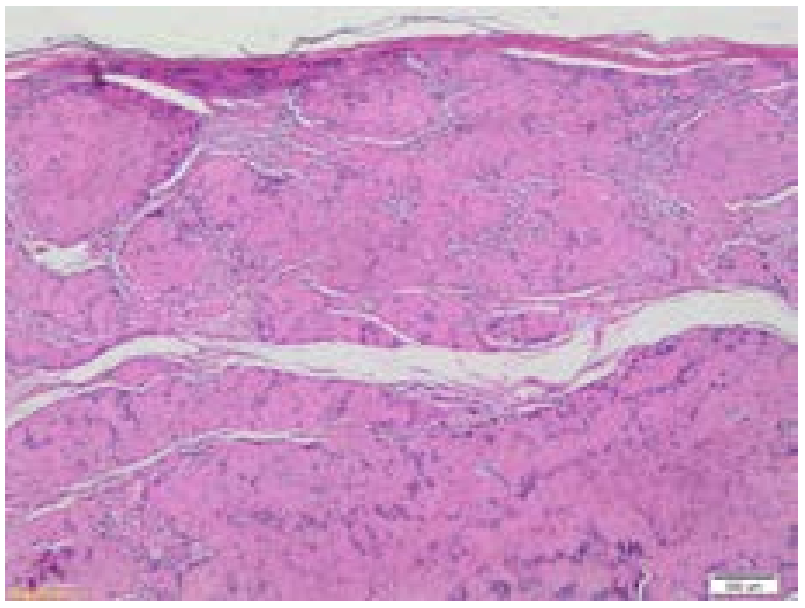

Figure 3. 4x magnification of neoplasm showing streaming fascicles of spindle-shaped cells.

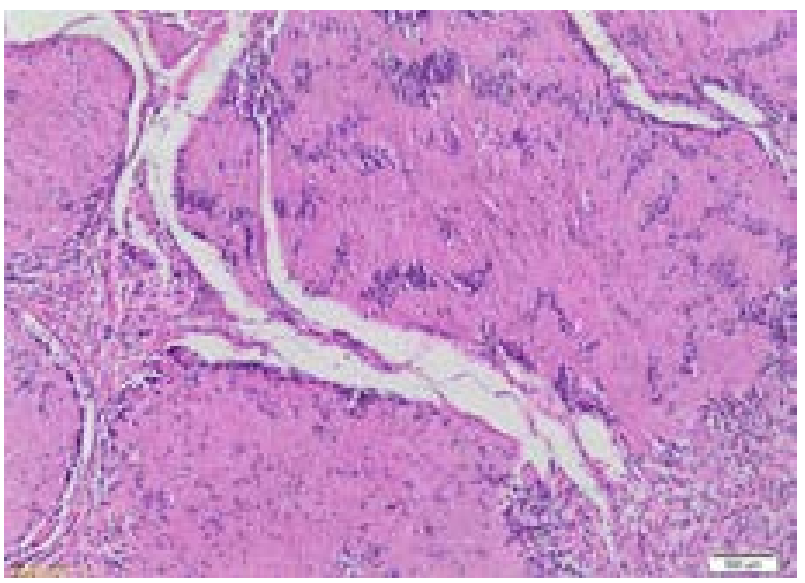

Figure 4. Streaming fascicles of spindle-shaped cells forming palisaded arrangement ("Antoni A area) around central acellular, eosinophilic areas representing Verocay bodies (yellow arrow) and "Antoni B" area (red triangle).

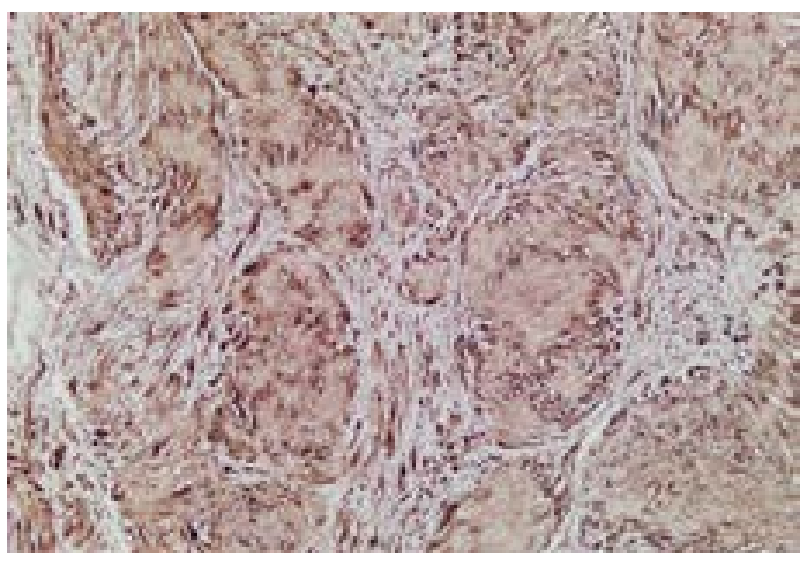

Figure 5. $10 \times$ magnification of S100 positive stained nuclear and cytoplasmic components of spindle-shaped cells. 
disease and in 3) Schwannomatosis, a non-hereditary disease characterized by multiple subcutaneous and intradermal Schwannomas along with variety of intracranial tumours. ${ }^{16,21}$

Histologically Schwannomas are usually encapsulated and shows proliferation of spindle shaped-shaped cells, which assume two different patterns. The hypercellular areas, so-called Antoni type A, consists of spindle shaped cells organised in a palisaded pattern usually around eosinophilic areas, forming the so-called Verocay bodies. The hypocellular areas, so-called Antoni type B, are less organised and the spindle cells are randomly arranged within a loose myxomatous stroma. ${ }^{2}$ The prognosis of Schwannoma is favourable and no malignant transformation has been reported, local recurrences are rare and this has been associated with incomplete enucleation of the tumour. ${ }^{1,10,16}$

The preoperative diagnosis of intra-oral Schwannomas are challenging. The most commonly applied imaging method is magnetic resonance imaging (MRI). ${ }^{6} \mathrm{MRI}$ or computed tomography (CT) may be significant in outlining tumour margins, composition and identifying any associated tumour infiltration. These imaging techniques are useful guide for surgical mapping prior to biopsy, which is required to arrive at a definitive diagnosis. ${ }^{12,20}$

Surgical resection of Schwannomas located on the lips is difficult. The intricate neuronal innervation of the lower lip requires precision during surgical removal, to prevent damage. Minimal damage during excision may cause significant morbidity such as impaired speech, aspiration, dysarthria, dysphagia, and paresthesia. ${ }^{20}$ A diagnosis of lip Schwannomas of the lip is very rare and is often misdiagnosed in early lesions. A differential diagnosis of lip Schwannomas is often only regarded until a more progressive stage of growth and subsequent cosmetic disfigurement occurs. To our knowledge there have been 3 previous reports of Schwannomas arising in a previous site of trauma. ${ }^{7,13,17}$

Even though Schwannomas are not bluish in colour, a differential diagnoses of a mucocele should be included, as the colouration of a mucocele can vary depending on the lesion size, proximity to the surface and the elasticity of the overlying mucosa. ${ }^{23}$ We recommend other differential diagnoses to include a traumatic neuroma, labial minor salivary gland tumours, traumatic fibroma, or a swelling secondary to the initial trauma and a lipoma. ${ }^{16-18}$ Albeit rarely encountered, it is our recommendation that intra-oral Schwannomas be included in the differential diagnosis for asymptomatic, wellcircumscribed nodules or masses of the lower lip., 7,13,17,22

\section{References}

1. Cardoso CL, de Souza Tolentino E, Capelozza AL, Consolaro A. Schwannoma in the lower lip mucosa: Unexpected diagnosis. Quintessence International. 2010; 41(9): 769-771.

2. Handschel J, Heikaus S, Depprich R, Kübler NR, Yekta SS, Smeets R, Ommerborn M, Naujoks C. Intraoral schwannoma: review of the literature and presentation of a rare case. CRANIO®. 2012; 30(2): 150-153.

3. Joshi S, Acharya S, Chaulagain R. Schwannoma in lower lip-A case report. Journal of Society of Surgeons of Nepal. 2014; 17(1): 44-46.
4. Panchonia A, Kulkarni CV, Mehar R, Mandwariya S. Schwannoma presenting as papilloma-a diagnostic dilemma. Oral \& Maxillofacial Pathology Journal. 2013; 4(2): 376-378.

5. da Silva LF, Duarte BG, Boiça BA, Rocha-Junior HV, PereiraStabile CL. Intraoral schwannoma: a case report. Oral and Maxillofacial Surgery. 2013; 17(4): 319-21.

6. Özgür A, Bedir R, Co-kun ZÖ, Erdivanlı ÖÇ, Terzi S, Dursun E. Schwannoma of the upper lip: A case report. Journal of Oral and Maxillofacial Surgery, Medicine, and Pathology. 2015; 27(6): 843-5.

7. Ravindran C, Siroraj P, Deepak C, Narasimhan M. Intraoral neurilemmoma of mental nerve mimicking as traumatic fibroma: An unusual presentation-A case report and literature review. Journal of Oral and Maxillofacial Pathology: JOMFP. 2017; 21(1): 124-128.

8. Pfeifle R, Baur DA, Paulino A, Helman J. Schwannoma of the tongue: report of 2 cases. Journal of Oral and Maxillofacial Surgery. 2001; 59(7): 802-4.

9. Lollar KW, Pollak N, Liess BD, Miick R, Zitsch III RP. Schwannoma of the hard palate. American Journal of Otolaryngology. 2010; 31(2): 139- 40.

10. Baderca F, Cojocaru S, Lazar E, Lazureanu C, Faur A, Lighezan R, Alexa A, Raica M, Valean M, Balica N. Schwannoma of the lip: case report and review of the literature. Rom $\mathrm{J}$ Morphol Embryol. 2008; 49(3): 391-8.

11. Yang SW, Lin CY. Schwannoma of the upper lip: case report and literature review. American journal of otolaryngology. 2003; 24(5): 351-4.

12. Priya R, Virmani N, Dabholkar JP. Schwanomma arising from mental nerve: a rare entity. International Journal of Scientific Reports. 2016; 2(10): 265-67.

13. Upadhyay S, Bhavthankar J, Mandale M, Humbe J. A diagnosis of an unusual lower lip swelling: Schwannoma. Nigerian Postgraduate Medical Journal. 2017; 24(3): 191.

14. Hajong $R$, Hajong $D$, Naku $N$, Sharma G, Boruah $M$. Schwannoma of upper lip: report of a rare case in a rare age group. Journal of Clinical and Diagnostic Research: JCDR. 2016; 10(8): 10-11.

15. Kulkarni GH, lqbal EJ, Kulkarni HS, Khaji SI, Biradar JM. Schwannoma of lower lip: an unusual case report and review of literature. International Journal of Medical Science and Public Health. 2015; 4(12): 1781-4.

16. Bansal R, Trivedi P, Patel S. Schwannoma of the tongue. Oral Oncology Extra. 2005; 41(2): 15-7.

17. Desai J. An unexpected and rare outcome of a common nodular mass on upper lip in a pediatric patient with a history of trauma-Schwannoma. National Journal of Maxillofacial surgery. 2019; 10(1): 102.

18. Kamboj M, Shreedhar B, Husain B, Husain P. Oral Schwannoma of Upper Lip-Report of a Case. 2014; 3(9): 59-61.

19. Pandya, D., Nagarajappa, A.K., Ghate, S. and Pathak, S., NEURILEMMOMA OF UPPER LIP: A RARE CASE REPORT International Journal of Medical and Applied Sciences 2015; 4(4) 38-42.

20. Sitenga J, Aird G, Vaudreuil A, Huerter CJ. Clinical features and management of schwannoma affecting the upper and lower lips. International Journal of Dermatology. 2018; 57(9): 1047-52.

21. Moreno-García C, Pons-García MA, González-García R, Monje-Gil F. J. Schwanoma of Tongue Maxillofac. Oral Surg. 2014; 13(2): 217-221

22. Nerune SM, Potekar RM, Rodrigues LD, Mestri NB. Swelling of the Upper Lip... Not always a Mucous Retention Cyst!!. Journal of Krishna Institute of Medical Sciences (JKIMSU). 2017; 6(2): 120-122.

23. Chaitanya P, Praveen D, Reddy M. Mucocele on lower lip: A case series. Indian Dermatology Online Journal. 2017; 8(3): 205-207. 